\title{
Agency-Structure Relation in Social Sciences: Reflections on Policy Implementation
}

\author{
D. Daniel Kipo ${ }^{1}$ \\ ${ }^{1}$ Department of Administration and Organization Theory, University of Bergen, Norway \\ Correspondence: D. Daniel Kipo, Fantoft Studentboliger, P. O. Box 442, 5075 Bergen, Norway. E-mail: \\ dandkipo@yahoo.com; Donwazum.Kipo@aorg.uib.no
}

Received: September 3, 2013 Accepted: October 11, 2013 Online Published: December 29, 2013

doi:10.5539/ass.v10n2p18

URL: http://dx.doi.org/10.5539/ass.v10n2p18

\begin{abstract}
The paper discusses important and highly contested agency and structure issue in philosophy of social science. The agency-structure relation focuses on autonomy and control. It draws more insights from Giddens thinking. Also, the paper discusses agency-structure relation in policy implementation. Discussions start with conceptualizations of agents, agency, structure and power relations between agency-structure. The paper specifically highlights problematics in agency-structure and relates them to policy implementation.
\end{abstract}

Keywords: agency, structure, power, structuration, public policy, policy implementation

\section{Introduction}

Agency and structure are key building blocks in the social sciences from sociology to other disciplines. Although they lack precise definitions within sociological theory, they remain crucial as there is an enduring debate between the two concepts in social theory. Anthony Giddens conceptualizes agents as knowledgeable individual actors, with more willful power and perpetrators of action. Agents are active and creative persons who are engage in continual flow of action. Agents continually monitor their activities and expect other agents to do same-reflexive monitoring of individual activity and others (Giddens, 1984). Also, agents continually maintain 'theoretical understanding' of their activities-rationalization of action. Agents are competent beings capable of explaining what they do. Agents have intentions for doing something and they have reasons for doing so. In addition, Giddens opines that while competent agents can nearly always tell or report discursively about their intentions, reasons for acting the way they do, they cannot necessarily do so for their motives. The problematic with Giddens thinking is about agents motives, whether agents' day-to-day conduct is directly motivated by themselves or agents' motives are structurally determined.

There are consequences of agents' action, some consequences are known others are unknown (unintended consequences). Some consequences may affect agent 'doing' action or affect other individuals and or larger society. The consequences of what agents do, intentional (willful) and or unintentional lead to change of events. Such change of events would not have happened if actor(s) had behaved or acted differently. The issue is on what agents 'do' and consequences of what has been done-within agent's own control. For instance an agent at surgery theatre sees lights during the day; then the agent decides to put off the light but ends up switching off whole source of power to surgery theatre which affected surgical operations in the theatre. In this scenario, agent acted freely and intentionally in switching off light in the theatre. But the agent's action (switching off light) brought about 'unintended consequences'-that is disruption of surgical operations and the subsequent arrest and the prosecution of agent by state. This example shows that agents' are capable of acting independently in relation to structure, with single event and chain of consequences. On the other hand the state (structure) is able to constrain agents through rules, as illustrated in above scenario. But the conceptual problematic here is on separation of intentional acts/action from unintentional acts/action and the separation of unintentional doings from unintended consequences of doing.

It is important to note Giddens practical consciousness of social actor-as capacity of human subject in social action and social structure. In Giddens perspective action refers to human beings (agents) and the aggregate of action create and reproduce social structure in which action is embedded. Social structure in Giddens view is a product of action. Giddens thinking illustrates that the relationship between agents and structure is that of 'autonomy and control'. This means agents have the capacity to act freely and are capable of creating social 
structures which in tend control or put some limitations on agents. To be an agent/actor means capable of exerting some degree of control over structures (social relations) in which the agent is "enmeshed" (Sewell, 1992, p. 20; Giddens, 1984). This conception implies actors/agents have capacity to transform social relations to some degree.

\section{Agency}

Agency is the capacity of individuals to act independently of social structures in making their own decisions and choices (Giddens, 1979; 1984). Other theorists view that it is individuals who make and remake their world. Methodological individualism, ethnomethodology social phenomenology and interactionism are theoretical systems which share this view. All human beings have the capacity for agency-for forming intentions, capacity for desiring and acting creatively (Sewell, 1992). This is an indication that all members of society exercise some amount of agency in the conduct of their daily activities or lives. Humans are born with highly generalized capacity for agency, as analogous to humans' capacity to use language. However agency is formed by specific cultural schemas and resources made available to a particular person's social milieu. Cultural schemas such as group culture rather than individuals, culture of particular ethnic group as in African and other parts of the world. Culture has influence on individuals, for instance extended family members mobilization of resources (be it financial) for the welfare of their members in time of ill-health or economic crisis is example of cultural schema. Sewell perspective on agency implies the particular form agency takes is culturally and historically determined. This depicts influence or control of structure on agency in social relations (Sewell, 1992). Sewell views complement Giddens thinking on agency-structure relation in terms of autonomy and control (Giddens, 1984; 1979).

In addition, Sewell indicates agency varies due to their occupancy of different social positions in society. Some individuals due to their positions have more access to resources and exercise more influence over others. Occupancy of different social positions can be by social prestige, wealth, class, ethnicity, sexual preference, gender, occupation or education. These form basis of people knowledge of different schemas and access to kinds of resources, thereby exercising different transformative action (Sewell, 1992). For example, person who occupies the position of national program manager has far more influence over local level program manager or a university dean has far influence on the making and implementation of university programs than a student in the same university. The influence that the university dean has over student is that of power relation based on the positions they occupied in organizations or society. Agency does not mean equal power or influence; some have more transformative action (power) than others. Structures empower agents differently; this implies human agency and social structures have different power levels (Sewell, 1992; Giddens, 1984). Agency characterizes all persons (personal agency). But the agency exercised by persons is collective in its sources and mode of exercise. Thus, agency is collective as well as individual-dualism (Sewell, 1992, p. 21).

\subsection{Agency-Power Relation}

Giddens perspective on agency-power relation is based on capacity of individual to "make a difference" to pre-existing state of affairs. For instance, the ability of an individual to change course of events (for example, A makes B to move in the direction B would not have moved (Giddens, 1984, p. 14). This capability of an individual to "make a difference" implies exercise of power. Giddens says any agent that loses this capability to "make a difference" in course of events ceases to be an agent. Agency logically involves power in the sense of 'transformative capacity' and power is closely linked to agency from Giddens thinking.

Power is a complex and a highly contested concept in the social sciences. Most conceptions of power reflect dualism of subject and object. Lukes perceives power as the capacity to achieve results you want. Lukes sees power as being vested in an agent/individual or social actor who exercises power to achieve desire results over another actor or agent. Lukes defines power as "A exercises power over B when A affects B in a manner contrary to B's interests (Lukes, 1974, p. 34). Max Weber sees power as capacity of an individual or actor to realize his or her will against the will of others in social action. Weber conception of power is that one actor exercises power over another actor (Weber, 1946a.). Luke and Weber conceptions of power suggest dominance of the individual will and desire over another individual or over collective wills and desires. This conceptualization of power in terms of agency misses power of social structures which mold human personality. Here, I note agents wield power and power is not equal among agents in the social world.

\section{Structure}

I look at connections of power in relation to structure. Lukes and Weber conceptions of power as discuss above contrast sharply with other scholars' particularly Parsons and Foucault who conceptualize power as 'property of society or the social community' (Giddens, 1984, p. 15). If power is property of society or social community, 
then this make scope of power as too broad. Parsons and Foucault conceptions indicate power is vested in groups, communities which they exercise for their common good against individual and sectional interest and will. Bachrach and Baratz have different conception of power. They opine power has two 'faces'. One 'face' represents capability of actors (agency) who make decision in their favour. The other 'face' is where mobilization of bias is built into institutions-structures. These theorists' perspectives I discuss above reflect dualism of subject and object and zero-sum conceptions of power. But Giddens thinks otherwise as he defines power as 'transformative capacity'. He conceptualizes power relations as 'regularized relations of autonomy and dependence' (Giddens, 1979, p. 6). Giddens conception of power does not reflect dualisms of agency and structure; it rather reflects duality of structure in power relations. This is what he calls "dialectic of control" in social systems. By implication, Giddens view structure as implicated in power relations and power relations as implicated in structure (Giddens, 1984; Fielding, 1988). Giddens power is not intrinsically link to attainment of sectional interests (individualist or societal or communal interest) but duality or dialectic. The conceptual dilemma is whether power reflects dualism or duality of structure.

\subsection{Giddens' Duality of Structure}

Structure is conceptualized as 'external' to human action (agency); it serves as constraint on activities of an independently constituted subject. This conception of structure is related to dualism of social object and subject, macro-micro levels of analysis where society is treated as collective reality and individuals as units of analysis. This characterizes ontology of social sciences. Anthony Giddens conception of structure differs sharply from those dualisms of subject and social object, macro and micro or structure and action. To Giddens structure cannot be analyze or conceptualize separately from action. Structures are made, maintained and changed through human actions (agency). To him structure is intrinsically link to agency and societies/collectivities would cease to exist if all agents involved disappeared. What I see in Giddens conception of structure is that it refers to collectivity in which humans are part.

Giddens also link structure to rules and resources. He defines structure as "rules and resources recursively involved in institutions" (Giddens, 1984, p. 24). Institutions are "the more enduring features of social life" (Ibid). Rules and resources are medium of actors' social interaction. Rules constrain action while resources make action possible, treating resources as enabling aspects of structure. Giddens sees structure and agency as dialectical rather than dualism. This explains Giddens core ontological notion of duality of structure. Duality of structure involves social practices of actors and collectivities. Social practice as unit of investigation has both a structural and an agency feature.

Mouzelis made internal critique and reconstruction of Giddens theory. He criticized Giddens reduction of structure-agency dualism into duality as incomplete. Giddens conception that structures always constrain and enable actors is also criticized for inability to focus on degrees of constraint within or between systems (Mouzelis, 1995; Kieran, 1998). Mouzelis conception of 'dualism' suggests sort of 'distance' between actor and structure (Mouzelis, 1995). Archer made efforts to develop coherent and an empirically profitable conception of structure and agency. She made strong effort to connect theory and research. Her analytic dualism-claims that effective sociological research depends on clear distinction between actors (agents) and structures instead of fusion of the two concepts. Researchers and theorists must see societies and individuals as different entities in their analysis. She fused analytic realism with critical realism (Archer, 1995; Kieran, 1998, p. 516; Archer, 1982).

\section{Agency-Structure: Theoretical Insights}

Philosophers of science developed conceptions of individualism and holism and this debate continues along methodological individualism and methodological holism (two non-relational philosophies of social science). While methodological holists focus on theories which explain social phenomena and claim social wholes are irreducible to theories about individuals and that social whole must be the bedrock of social scientific theories. Individualists on the other hand view social wholes as reducible to and explainable in terms of individuals' acts, choices as in rational choice theories, neo-classical approaches in economics (Vatn, 2005; Popper, 1948; Hayek, 1949; cited in Fay, 1996). Past social science philosophers, theorists or thinkers theoretical insight was either individualism or holism, at least in some part of their works. For example, Weber's social action was seen as paradigmatic of individualism while Durkheim's ideas on social facts were seen as model for holism. The social world, is it really made up of only individuals or collective entities?

Some social science theorists made a tacit development of methodological relationism as an alternative to individualism and holism (Sztompka, 1994). Methodological relationism appears to provide a base for the relationship between agency and structure in social theories. Methodological relationism is considered to be 
broader and less confining when compared to methodological individualism and methodological holism. Contemporary social theorists in their construction of social theories look at relation between agency and structure rather than as either individualists or holists. According to Sztompka social theorists need to create a philosophy of science that is adequate in their theoretical needs or to create a "fully formed methodological relationsm" to parallel conceptions of individualism and holism (Sztompka, 1994, p. 5). Theoretical problematic is whether social theories should be developed, constructed or approached as either individualism or holism or be developed as agency-structure relation (theoretical relationism). What about theoretical integration?

\subsection{Towards Agency-Structure Integration}

How is social theory approached or developed? How is social reality shaped? Scholars have different theoretical approaches and different conceptions about social reality; thinkers may agree to some approaches and may differ in some aspects. In this respect, I look at theoretical insights of thinkers like Giddens, Bourdieu and Alexander. These three thinkers agree on theoretical synthesis as way to transcend agency-structure problem. I first look at Giddens' approach or conception. Giddens' theoretical approach has proposition that structure is always both enabling and constraining (by structuration theory). To Giddens human societies, societal totalities or social systems will not exist without human agency. It is human agency that reproduces and transforms social system in remaking what is already made for continuity. This implies human action reproduces social structure and can lead to social change. Giddens' theoretical approach (structuration theory) does not take extreme position as either individuals (human agency) or society (social forces) that shapes our social reality/social world (Giddens, 1984). This means there is no reductionism in structuration theory. Structuration theory sees agency and structure as complementary forces where structure influences agency and agency is capable of changing structures. However, has Giddens's structuration theory resolves the oppositions of subjectivity-objectivity, micro-macro, et cetera in understanding or explaining social phenomena in social sciences?

Durkheim in his work, The Rules of Sociological Method conceptualizes structural properties or societal totalities as external to activities of individuals. This conception implies structure has constraining influence over action (individuals). This is contrary to Giddens structuration theory. Durkheim constraint is that structural properties existed before individuals and they outlast lives of individuals born into them (society). Durkheim emphasizes the significance of societal structure over agency and believes the social world cannot be explained by actions of individuals-human agency (Durkheim, 1895; Giddens, 1984). Durkheim also stresses constraining elements or powers of socialization. Durkheim later realizes that socialization is not only constraining actions of individuals but enabling as well. By implication, socialization serves as constraint and enablement. This conception of societal totalities as constraint to individual action is problematic in Durkheim's own analysis. This is insight for social inquiry.

\subsection{Thinkers Divergence Views}

Even though theorists and thinkers like Giddens, Bourdieu and Alexander aim at synthesizing or transcending agency-structure issue, they also have some differences in their theoretical insights or conceptions. I look at some of their differences in an attempt to compare one thinker or theorist conception with another. To start with Bourdieu, Bourdieu field is seen as contest of domination. Some fields are more dominant than others, for instance field of power (politics) is dominant over other fields. Bourdieu theorization of the logic of practice is seen as contest of domination in homologously organized fields (Friedland, 2009). Domination of capital, economic capital is dominant over other forms of capital. There is dominance between groups or classes, one group or class looks dominant over others through distinctiveness of their culture and scholarly titles. This constitutes the organization of social domination. In Bourdieu Distinction, there is existence of legitimate principle of domination in the field where there is class struggle between the dominant and the dominated (mass) The dominated classes see themselves as 'culturally unworthy' (poorer with economic and cultural capital) when compare to 'dominant's culture'. Efforts of the dominated class or classes to influence the appropriation of properties, to define legitimate properties and legitimate mode of appropriation have failed while the dominant class culture prevails (Bourdieu, 1984, p. 251; Friedland, 2009). There is struggle between agents and institutions for legitimacy, authority and recognition in Bourdieu's field. This shows there is power in Bourdieu's field. Power is seen as end and a determinant of practice. There is power relation between men and women (power of sex) in their quest for recognition and esteem. With dominance of men (masculine domination) over women (feminine) in 'reality' of social order (Bourdieu, 2001). What I note from Bourdieu is that there is an inter-play of dominance and power in Bourdieu's field. This Bourdieu conception of power differs sharply from Giddens conception.

Giddens does not see power as contest, struggle between groups, classes, he rather sees close relation between 
power and agency. Giddens view is any individual in a social relationship irrespective of that person's position in the relationship has certain amount of power over the other. Giddens says power relations are always two-way, power is a relation of autonomy and dependence in social interaction. Giddens sees power in both agency and structure where power is view as transformative capacity (human agency) and domination (structural quality-resources). This I note from Giddens that power is a relational concept linking transformative capacity of actors and structures of domination. Giddens structures of dominion refer to asymmetries resources used to sustain power relations in social interaction. Giddens power is not about struggle for recognition and domination of one structure over the other in social life but rather power is about interaction and elements of production of interaction between agents (human agency) and social systems (structures) (Giddens, 1984; 1979). Thus, Giddens does not reduce social life to struggle for power.

Power and domination are not prominent in Alexander's search for multi-dimensionality over one-dimensional conception of society or social life. Alexander sees social life in materialistic terms (drives, appetites) and normativistic (values, ideals) as action while individuals (micro) and collectivity (macro) as order. Alexander views objects of external, material environment and ideals as constraining humans. The constraining power is more influential in the external, material environment than in ideals. Alexander treats materialism and idealism as in 'dual' form in terms of their power relation. Alexander view on power differs from Bourdieu and Giddens views on power.

Apart from power and domination difference, I note some difference(s) in their conception of structures and agents. In Distinction, Bourdieu sees social structure as reproduction derives from its internalization as cognitive classifications, tastes or preferences with emphasis on institutions and their effect on social and cultural patterns. Within these classifications, tastes, preferences there are the dominants and the dominated groups. This differs from Alexander's social structure ('order') in terms of micro/macro dimensions and Giddens' structure of 'rules and resources' recursively implicated in reproduction of social systems. Giddens structures do not exist as concrete objects by time and space, rather they exist as virtual ideas, schemas in human brain ('memory traces') which are put into practice in different ways (Giddens, 1984).

Bourdieu conception of agents (habitus) contrasts other thinkers or theorists' conception of agents. Habitus assumes that practices have commonsense, reasonableness and intention less but with 'objective meaning' (Bourdieu, 1977; Friedland, 2009). Bourdieu habitus is opposed to Alexander agents ('action') in terms of instrumental/materialist versus ideal/normative and Giddens knowledgeable agents' intentional acts. Also, Bourdieu theory of practice organized through world of doxa-the taken for granted everyday lifestyle contrast Giddens' reflexive theory which sees human actions/acts as lifestyle choices agents make and discursive world of ortho-and heterodoxy" (Friedland, 2009, p. 889).

From my discussions on the agency-structure issue, I observe social world is not exclusively made of collective entities but also consist of individuals. My reflections are that in studying a social phenomenon (health care), actors (agents) and factors (structure) are crucial and should be identified. It is based on these reflections; I examine agency-structure relation in policy implementation.

\section{Agency-Structure Relation in Policy Implementation}

This section discusses agency-structure relation in policy implementation study. The focus is on policy theorists conceptions of agency and structure (effective policy implementation). Policy theorists' conceptions of agency-structure in policy implementation study does not necessarily reflect same conceptions of the sociological theorists and thinkers like Giddens, Bourdieu, Alexander among others as I discussed earlier. The purpose of this section is to discuss the dilemmas of agency-structure issue in policy implementation study in general and some implications in particular locality (the case of national health insurance scheme at local level in Ghana).

\subsection{Policy Implementation: A Construct}

Policy implementation is a construct due to its multi-disciplinary, multi-level (high-low) and multi-focus nature (actors, loci, layer and styles). Policy implementation is across many fields of study from sociology, economics, education, political science to public administration-governance and new public management. Policy implementation as a construct is understood in different ways or diverse perspectives. There is fluidity in definition as well as conception of policy implementation as either in terms of policy process/output or outcome or both. Also, due to its multi-disciplinary nature some scholars and students have often face challenge of explaining policy implementation. This complexity of policy implementation is buttress by some observation in Pressman and Wildavsky "if implementation is everywhere, as one of the authors suggested in another connection, is it ipso facto nowhere? ... No doubt this is why students of implementation complain that the 
subject is so slippery; it does depend on what one is trying to explain, from what point of view, at what point in its history" (Pressman \& Wildavsky, 1984, p. 164). Beside this, there are other dilemmas as to what theoretical approaches or perspectives to adopt in studying policy implementation. The question of whether to adopt top-down, bottom-up or mixed approach is keenly contested/debated among scholars. Also, there is methodological dilemma whether to focus on individuals (micro/psychological) or collective approach (macro/group/institutions/organizations) or both is highly debatable.

\subsection{Effective Policy Implementation}

Policy theorists and scholars have different conceptions of effective policy implementation. What is 'effective' policy implementation? Effective policy implementation is defined as "keeping to the original intent of the public officials who had ratified the policy" (Howlett \& Ramesh, 2009, p. 164). This conception suggests hierarchy of authority or chain of command exist to ensure policy is successfully implemented in terms of achieving goals and objectives. This conception represents 'top-down' theorists approach to policy implementation; they see effective policy implementation towards achieving policy goals and objectives (Pressman \& Wildavsky, 1984; Van Meter \& Van Horn, 1975). The dilemma is whether effective policy implementation is based on carrying out 'policy intent' or not.

Lipsky in his 'street-level bureaucratic model' conceptualizes effective policy implementation as actions of local level individuals (actors). According to him, local level individuals do not only make policies but implement policies. This conception assumes a 'bottom-up' approach where actions, goals and desires of agents matters most. This conception focuses more on human agency. On the other hand Lipsky recognizes structures as "crowded offices" in which local level individuals occupy. Lipsky does not see 'structure' as completely constraining but enabling factor since actors in some circumstances make and execute policies (Lipsky, 1980). Lipsky worldview is about actions local level officers take to solve local problems rather than relying more on directives from top offices. Here, I note Lipsky's conception contrast policy theorists who emphasize collectivities (groups, organizations or institutions) as responsible for effective policy implementation. How is Lipsky local level individuals' conception related to agency? How is agency conceptualized in policy implementation study?

Agency is a highly contested concept among policy theorists in policy implementation. Some policy theorists link agency to actions and activities of individuals-human agency (Lipsky, 1980; Sabatier, 1986). Other policy theorists link agency to structure-actions of implementing institutions and organizations in society (Mazmanian \& Sabatier, 1983; Hall \& O'Toole, 2000). Principal-agent theorists see agency differently. Agency is seen as policy implementers (actions of lower staffs). Also, agency is seen as 'principals' (policy makers like politicians and senior public officials). All these conceptions involve human agency. These conceptions of agency appear to be a dilemma between actions of individuals and actions of implementing institutions (structure) or agency should involve the actions of both individuals and structure? The conceptions of agency are insightful for my study on the implementation of public policy.

Agency-structure relation, some policy theorists view the two concepts as intrinsically linked (synthetic relation). In this regard, Winter developed integrated implementation model which attempts to transcend the dichotomy between agency (actor-based) and structure (groups, organizations-based). Winter's theoretical argument is towards synthesizing rather than polemical theorizing. In this respect, Winter's model identifies key clusters of factors, actors theorize to affect implementation output and outcome. These factors and actors include policy formulation and design; organizational and inter-organizational behaviour; actions, behaviour and perception of street-level bureaucrats (actors); target groups behaviour; changes in society and socio-economic conditions. They are crucial for effective policy implementation (Winter, 2003). These key factors and actors can facilitate or inhibit policy implementation. How is the policy implementation field really conceptualized, is it in terms of actors, factors or both?

Aryee in his work Saints Wizards Demons and System see effective policy implementation as involving key policy actors (agents) and environmental factors (structures or systems). He sees actors and factors conception as a way to solving agency-structure problem in policy implementation study. Aryee's conception makes particular reference to Ghana and other African countries. To him key policy actors and factors must be taken into consideration for successful policy implementation. These key policy actors include committed politicians and bureaucrats ('saints'), appropriate policy analysts ('wizards'), hostile and apathetic groups ('demons'). On key factors emphasis is place on identifying environmental factors ('systems') that work against policy implementation (Aryee, 2000). Aryee's theoretical insight is toward multi-dimensional perspective, key actors and factors play important role in implementation. Social scientists and scholars in policy field have the task on 
how to identify key policy actors and factors in field (social world or society). This task looks challenging but insightful.

\section{Agency-Structure Relation: Implications for the Implementation of National Health Insurance Scheme in Ghana}

From various perspectives I discussed in this paper on agency-structure issue from key social theorists or thinkers like Bourdieu, Giddens and Alexander to policy theorists and thinkers including Winter, Aryee, Hjern and Porter and Hall and O'Toole Jr. it is obvious that there is no single definition or conception of the social world. There is also no generally acceptable definition or conception for effective policy implementation. The paper notes while some theorists conceptualize the social world from one-dimensional perspective (agency-structure dichotomy) others adopt multi-dimensional view in attempt at transcending agency-structure dualism. Despite the conceptual, definitional, methodological and theoretical dilemmas from various scholars, thinkers and theorists discussed in the paper, the following key elements cut across agency-structure relation in general and effective policy implementation in particular.

First, agency is related to actions, habitus and agents. And structure is related to social order, field and rules and resources (Alexander, 1982; Bourdieu, 1977; Giddens, 1984). For these social theorists agency and structure concepts are intrinsically linked as found in their theories of multi-dimensionality, habitus field theory and structuration theory respectively. Secondly, in policy implementation study agency is related to individuals' actions, behaviour, choices (human agency), while structure is related to collectivities (target groups, institutions or organizations). These policy theorists and scholars perspectives emphasize both agency-based (key policy actors) and structure-based issues (groups, organizations and institutions). Policy theorists see effective implementation as multi-dimensional, multi-level (high-low) and multi-focus (actors, factors, loci, layer and styles). These policy theorists' theoretical perspectives are towards synthetic relation of agency-structure and synthesizing features of both top-down and bottom-up approaches (Winter, 2003; Aryee, 2000; Hjern \& Porter, 1981; Hall \& O’Toole, 2000).

Using these theoretical insights as point of departure, effective policy implementation will be examine at individual level, which will involve policy beneficiaries' and other policy actors at community level. The aim is for them to share their views on (trust, timeliness to healthcare services and access to quality health care). At the institutional level, key factors to examine are implementation structure, inter-organizational relations (cooperation and co-ordination) and resource mobilization capacity of implementing institutions. Also, environmental factors such as socio-economic conditions, cultural and political conditions at local level are to be considered. Some key questions will include these: what actors and factors may account for effective policy implementation at local level in general? What actors and factors may explain implementation variations between public and private health care facilities? In what way or ways can agency and structure relation in policy implementation be enhance at local level?

\section{References}

Alexander, J. C. (1982). Theoretical Logic in Sociology. London: Routledge \& Kegan Paul Ltd.

Archer, M. S. (1982). Morphogenesis versus structuration: On Combining Structure and Action. British Journal of Sociology, 33(4), 455-483. Retrieved from http://www.jstor.org/stable/589357 http://dx.doi.org/10.2307/589357

Askvik, S., Ishtiaq, J., \& Dhakal, T. N. (2011). Citizens' trust in public and political institutions in Nepal. International Political Science Review, 32(4), 417-437. http://dx.doi.org/10.1177/0192512110377437

Ayee, J. R. A. (2000). Saints Wizards Demons and Systems: Explaining the Success or Failure of Public policies and Programmes. Accra: Ghana Universities Press.

Bourdieu, P. (1977). Outline of a Theory of Practice. Cambridge: Cambridge University Press. http://dx.doi.org/10.1017/CBO9780511812507

Bourdieu, P. (1984). Distinction: A Social Critique of the Judgment of Taste. Cambridge, MA: Harvard University Press.

Bourdieu, P. (1990). The Logic of Practice. Cambridge: Polity Press.

Bourdieu, P. (1991). Language and Symbolic Power. Cambridge: Polity Press.

Bourdieu, P. (2001). Masculine Domination. Stanford, California: Stanford University Press. 
Coleman, J. S. (1966). Foundations for a theory of collective decisions. American Journal of Sociology, 71(6), 615-627. http://dx.doi.org/10.1086/224219

Dixon, K. (1973). Sociological Theory: Pretense or Possibility. London: Routledge \& Kegan Paul Ltd.

Douglas, M. (1966). Purity and Danger: An Analysis of Concept of Pollution and Taboo. London: Routledge and Kegan Paul. http://dx.doi.org/10.4324/9780203361832

Fay, B. (1996). Contemporary Philosophy of Social Science: A multicultural approach. Oxford: Blackwell Publishing.

Fielding, N. G. (Ed.). (1988). Actions and Structure: Research Methods and Social Theory. London: Sage Publications Ltd.

Friedland, R. (2009). The Endless fields of Pierre Bourdieu. Organization, 16(6), 887-917. http://dx.doi.org/10.1177/1350508409341115

Giddens, A. (1979). Central Problems in Social Theory: Action, Structure and Contradiction in Social Analysis. London: The Macmillan Press Ltd.

Giddens, A. (1984). The Constitution of Society: Outline of the Theory of Saturation. Cambridge: Polity Press.

Grindle, M. S., \& Thomas, J. W. (1991). Public Choice and Policy Change: The Political Economy of Reform in Developing Countries. Baltimore and London: The Johns Hopkins University Press.

Hall, T. E., \& O’Toole, J. L. J. (2000). Structures for policy implementation: An analysis of national legislation. Administration and Society, 31(6), 667-686. http://dx.doi.org/10.1177/00953990022019281

Hjern, B., \& Porter, D. O. (1981). Implementation structures: A new unit of administrative analysis. Organization Studies, 2(3), 211-227. http://dx.doi.org/10.1177/017084068100200301

Hollis, M. (1994). The Philosophy of Social Science: An Introduction. Cambridge: Cambridge University Press.

Howlett, M., Ramesh, M., \& Perl, A. (2003). Studying Public Policy: Policy Cycles \& Policy Subsystems. Canada: Oxford University Press.

Jarvie, I. C., \& Agassi, J. (1967). The problem of the rationality of magic. The British Journal of Sociology, 18, 55-74. Retrieved from http://www.jstor.org/stable/588590 http://dx.doi.org/10.2307/588590

Jenkins, R. (1992). Pierre Bourdieu: Key Sociologists. London: Routledge.

Kieran, H. (1998). Conceptualising constraint: Mouzelis, Archer and the concept of social structures. Sociology, 32(3), 509-522. Retrieved from http://journals.cambridge.org/abstract_S0038038598000066 http://dx.doi.org/10.1177/0038038598032003006

Lipsky, M. (1980). Street-Level Bureaucracy: Dilemmas of the Individual in Public Services. New York: Russell Sage Foundation.

Little, D. (1969). Religion, Order and Law. New York: Harper and Row.

Lukes, S. (1974). Power: A Radical View. London: Macmillan.

March, J. G., \& Olsen, J. P. (1998). The institutional dynamics of international political orders. International Organizations, 52, 943-969. http://dx.doi.org/10.1162/002081898550699

Mazmanian, D. A., \& Sabatier, P. A. (1983). Implementation and Public Policy. New York: University Press of America.

Momen, N. M. D. (2010). Challenges of Implementing Public Procurement Reform Initiatives in Bangladesh: The Case of Local Government Engineering Department (LGED). Department of Administration and Organization Theory, University of Bergen, Norway.

Mouzelis, N. (1995). Sociological Theory: What went wrong? Diagnosis and Remedies. New York: Routledge.

Pressman, J. L., \& Wildavsky, A. (1984). Implementation (3rd ed.). Berkeley, CA: University of California Press.

Rothstein, B. (1998). Just Institutions Matter: The Moral and Political Logic of Universal Welfare State. Cambridge University Press. http://dx.doi.org/10.1017/CBO9780511598449

Sabatier, P. A. (1986). Top-down and bottom-up approaches to implementation research: A critical analysis and suggested synthesis. Journal of Public Policy, 6(1), 21-48. http://dx.doi.org/10.1017/S0143814X00003846

Sewell, W. H. J. (1992). A theory of structure: Duality, agency and transformation. American Journal of Sociology, 98(1), 1-29. Retrieved from http://www.jstor.org/stable/2781191 
http://dx.doi.org/10.1086/229967

Shils, E. (1975). Centre and Periphery: Essays in Macrosociology. Chicago: University of Chicago Press.

Shils, E. (1976). Centre and periphery: Essays in macrosociology by Edward Shils. Canadian Journal of Political Science, 9(2), 337-338. http://dx.doi.org/10.1017/S0008423900043961

Skodvin, T., Gullberg, A. T., \& Aakre, S. (2010). Target-group influence and political feasibility: The case of climate policy design in Europe. Journal of European Public Policy, 17(6), 854-873. http://dx.doi.org/10.1080/13501763.2010.486991

Sztompka, P. (Ed.). (1994). Agency and Structure: Reorienting Social Theory. Amsterdam: Gordon and Breach Science Publishers S. A.

Van Meter, D., \& Van Horn, C. E. (1975). The policy implementation process: A conceptual framework. Administration and Society, 6(4), 445-488. http://dx.doi.org/10.1177/009539977500600404

Vatn, A. (2005). Institutions and the Environment. Cheltenham UK: Edward Elgar Publishing Limited.

Wacquant, L. J. D. (1989). Towards a reflexive sociology: A workshop with Pierre Bourdieu. Sociological Theory, 7(1), 26-63. http://dx.doi.org/10.2307/202061

Weber, M. (1946). In H. H. Gerth, \& C. W. Mills (Eds.), From Max Weber: Essays in sociology. New York: Oxford University Press.

Weber, M. (1978). Economy and Society. Berkeley: University of California Press.

\section{Copyrights}

Copyright for this article is retained by the author(s), with first publication rights granted to the journal.

This is an open-access article distributed under the terms and conditions of the Creative Commons Attribution license (http://creativecommons.org/licenses/by/3.0/). 